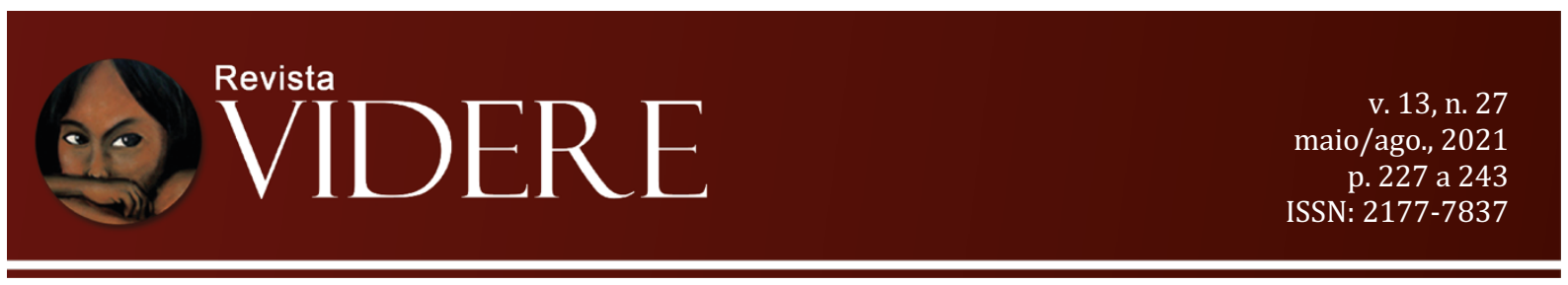

\title{
COLONIALIDADE DO CORPO FEMININO NEGRO: TRABALHO REPRODUTIVO NO PERÍODO ESCRAVOCRATA BRASILEIRO E JUSTIÇA RACIAL
}

\author{
COLONIALITY OF THE BLACK FEMALE BODY: REPRODUCTIVE WORK IN THE \\ BRAZILIAN SLAVE PERIOD AND RACIAL JUSTICE
}
COLONIALIDAD DEL CUERPO FEMENINO NEGRO: TRABAJO REPRODUCTIVO EN EL PERIODO DE ESCLAVITUD BRASILEÑO Y JUSTICIA RACIAL

\author{
Damaris Tuzino de Rezende \\ Mestranda em Direitos Coletivos e Cidadania (UNAERP) \\ damaristuzino@yahoo.com.br \\ OrcidID: https://orcid.org/0000-0002-2747-0841
}

Maria Cristina Vidotte Blanco Tárrega Doutora em Direito Empresarial (PUC-SP) Universidade Federal de Goiás (UFG) mcvidotte@gmail.com OrcidID: https://orcid.org/0000-0002-4805-4345

Resumo: O presente artigo tem por escopo analisar como se deu a colonialidade do corpo feminino negro e o trabalho reprodutivo da mulher negra durante o período escravocrata brasileiro, trazendo a dualidade entre o corpo para o trabalho e o corpo para o prazer. A partir de uma análise interseccionada entre racismo e sexismo, procurou-se debater como raça e gênero configuram feixes de opressão que atravessam os corpos femininos negros desde o colonialismo e permanecem até a contemporaneidade, de modo a produzir condições diferenciadas de acesso a direitos, inclusive direitos reprodutivos. Logo, pautando-se pelo método dedutivo, através de uma pesquisa exploratória bibliográfica e qualitativa, pretende-se abordar a hierarquia reprodutiva existente no Brasil, em que mulheres negras não alcançam com plenitude a autonomia sobre seus próprios corpos. Conclui-se que é urgente constituir a mulher negra enquanto sujeito político, identitário e não subalterno, rompendo com as violências históricas geradas pelo colonialismo e pelo processo de hierarquização de raças.

Palavras-chave: Colonialidade do corpo. corpo feminino negro. trabalho reprodutivo. justiça racial.

Abstract: This article aims to analyze how the coloniality of the black female body and the reproductive work of black women took place during the Brazilian slave period, bringing the 
duality between the body for work and the body for pleasure. From an intersecting analysis between racism and sexism, we sought to debate how race and gender configure bundles of oppression that cross black female bodies since colonialism and remain until contemporaneity, in order to produce different conditions of access to rights, including reproductive rights. Therefore, based on the deductive method, through an exploratory bibliographical and qualitative research, it is intended to address the reproductive hierarchy existing in Brazil, in which black women do not fully achieve autonomy over their own bodies. It is concluded that it is urgent to constitute black women as a political, identity and non-subaltern subject, breaking with the historical violence generated by colonialism and by the process of hierarchization of races.

Keywords: Coloniality of the body. black female body. reproductive work. racial justice.

Resumen: Este artículo tiene como objetivo analizar cómo la colonialidad del cuerpo femenino negro y el trabajo reproductivo de la mujer negra ocurrió durante el período esclavista brasileño, trayendo la dualidad entre el cuerpo para el trabajo y el cuerpo para el placer. A partir de un análisis de intersección entre racismo y sexismo, buscamos debatir cómo la raza y el género configuran haces de opresión que atraviesan los cuerpos de las mujeres negras desde el colonialismo y permanecen hasta la contemporaneidad, para producir diferentes condiciones de acceso a los derechos, incluidos los derechos reproductivos. Por lo tanto, con base en el método deductivo, a través de una investigación exploratoria bibliográfica y cualitativa, se pretende abordar la jerarquía reproductiva existente en Brasil, en la que las mujeres negras no alcanzan plenamente la autonomía sobre sus propios cuerpos. Se concluye que es urgente constituir a la mujer negra como sujeto político, identitario y no subalterno, rompiendo con la violencia histórica generada por el colonialismo y por el proceso de jerarquización de razas.

Palabras clave: Colonialidad del cuerpo. cuerpo femenino negro. trabajo reproductivo. justicia racial.

\section{Introdução}

As iniquidades raciais, no Brasil, foram construídas desde o período escravocrata brasileiro. Nesta fase, a mulher negra, para além de representar força de trabalho do colonizador branco, também vivenciava uma cruel exploração sexual, que colocava seu corpo atravessado por um conjunto complexo de opressões, articulando principalmente raça, gênero e classe. A interseccionalidade entre esses feixes de opressão configurou desvantagens históricas paras as mulheres negras que ainda atuam de maneira decisiva em sua posição social e econômica, uma vez que o corpo feminino negro ainda lida com os estereótipos e as imagens de subalternização herdados da escravidão: a mulata, a mãe preta e o trabalho braçal.

Dessa forma, o primeiro tópico do presente trabalho discorre acerca do corpo colonial da mulher negra e de como ele passou por um processo de objetificação que invisibilizou sua humanidade e contribuiu para que essa mulher não se enxergasse enquanto sujeito político não 
subalterno. O segundo tópico verifica que as mulheres escravizadas também tinham sua capacidade reprodutiva enquanto objeto de exploração, funcionando tanto como reprodutoras de mão-de-obra escrava quanto como amas de leite das crianças filhas dos senhores brancos.

Em seguida, no tópico três, analisa-se como a dominação do labor reprodutivo da mulher negra e de seu corpo desde o período escravocrata resultou na construção de uma hierarquia reprodutiva responsável por submeter o corpo feminino negro a um controle social contínuo que determina as condições de vida e de saúde das mulheres negras, limitando sua autodeterminação e seus direitos. A experiência da mulher negra ainda simboliza objetificação em uma perspectiva que entrelaça subordinação e histórico de servidão.

O objetivo do presente trabalho é, a partir de uma pesquisa exploratória bibliográfica e qualitativa, abordar a trajetória de significação do corpo da mulher negra durante o período escravocrata brasileiro, bem como discutir a exploração reprodutiva do corpo feminino negro nessa época e trazer dados atuais apontando a racialização do controle reprodutivo, que confere experiências sociais diferentes para mulheres brancas e negras.

\section{O corpo colonial da mulher negra}

A experiência da mulher negra escravizada é fortemente marcada pelo sexismo e pelo racismo, de maneira que essas formas de opressão se estabeleceram como partes estruturantes da ordem social e política vigente impostas por colonizadores brancos, causando um impacto profundo no destino das mulheres negras. Inicialmente, conforme HOOKS (2020, p. 37), "a mulher negra escravizada não era tão valorizada quanto o homem negro escravizado. Em média, o homem negro escravizado era mais caro que a mulher escravizada". O comércio de pessoas escravizadas, em princípio, era de homens negros, e só depois voltou-se com mais força para mulheres negras.

Com o intuito de estabelecer um processo de doutrinação que transformaria o seu humano africano livre em escravo, o homem branco colonizador se utilizava de diversas práticas de poder e tortura já durante a travessia em navios negreiros. No que tange à mulher negra, pesava primordialmente a subjugação através do estupro, servindo como um constante lembrete de sua vulnerabilidade sexual e subserviência ao escravizador.

O terror psíquico e a violência vividos por homens e mulheres negros durante a travessia do Atlântico eram apenas as primeiras etapas no propósito de destruir a dignidade humana dessas pessoas, eliminando seus nomes, reprimindo a consciência de sua liberdade e forçando-as a adotar a identidade de escravizado. O que restava dessa identidade estilhaçada 
era a desumanização de pessoas. Uma vez desumanizadas, são, portanto, produtos. E a fim de tornar seu produto vendável, "o escravizador precisava garantir que nenhuma criada negra recalcitrante envenenasse a família, matasse as crianças, incendiasse a casa ou oferecesse qualquer outra forma de resistência" (HOOKS, 2020, p. 44), já que entre os seus trabalhos estariam cozinhar, amamentar e limpar para o futuro comprador.

Em razão disso, mulheres africanas recebiam grande parte da violência ao longo da travessia dos navios, pois era preciso garantir que ficassem tão aterrorizadas a ponto de se sujeitarem passivamente à vontade do escravizador e do novo dono. "Enquanto as punições mais violentas impostas aos homens consistiam em açoitamentos e mutilações, as mulheres eram açoitadas, mutiladas e também estupradas" (DAVIS, 2016, p.26). Após a chegada ao Brasil, e ao longo de todo o período escravocrata, o corpo da mulher negra serviu como base de exploração braçal e sexual. Sua exploração ocorria no campo, em trabalhos domésticos, como reprodutora e como objeto de crimes sexuais perpetrados pelo homem branco.

A objetificação do corpo negro feminino o coloca enquanto território a ser colonizado, domado e sempre pronto a servir, seja no trabalho braçal, seja sexualmente. No que se refere aos estupros recorrentes, o objetivo político era obter absoluta submissão e obediência à ordem imperialista branca (HOOKS, 2020). É no corpo, segundo LOPES (2014), que as opressões sofridas pelas mulheres escravizadas se tornam visíveis, de modo que passa a ser considerado território político a partir do entendimento de que as mulheres negras compartilham de uma perspectiva singular, devido às particularidades que compõem seus próprios corpos, desde a diáspora até as experiências racializadas.

A opressão racial e sexista sofrida pela mulher negra no período escravocrata influiu na construção de sua subjetividade, e essa dimensão identitária está intrinsecamente relacionada com a dimensão política. Instaurada uma ordem arbitrária de poder empreendida pelo colonizador europeu, a colonialidade, em sua categoria “colonialidade do ser”, é responsável pela constituição da corporalidade negra. Isso tudo por meio de uma racionalidade eurocêntrica vinculada a um processo de objetificação racista que se mantém atualizado até hoje. A colonização "coisificou” os corpos colonizados, que, consoante FANON (2004), sofreram um processo de inferiorização produzido por meio de um duplo movimento.

Inicialmente, o corpo negro passou pelo processo econômico de perda da sua terra, autonomia, liberdade, que é justificado pela cor da pele. Somado a isso, há um segundo mecanismo referente à desculturação, pela qual o ser humano recém-chegado, sequestrado de sua terra e enviado forçadamente a outra, é obrigado a adotar uma linguagem diferente daquela 
em que nasceu. Este segundo mecanismo evidencia por si só a imposição de uma cultura e de um modelo eurocentrado de se viver.

Ainda de acordo com FANON (2008), a modernidade ocidental, ao definir um conceito de humano, por exclusão delimita tudo o que não é humano, cabendo ao sujeito civilizado intervir, empregar sua força e alterar o destino. Ao se demarcar como humano, o europeu também cria o não humano: o indígena, o africano, o árabe, o povo amarelo: o outro. Se o colonizador apenas vê a si próprio como razão, então a ideia de humanidade está sendo usurpada, pois ela é entregue a um único grupo. A desumanização, atrelada à condição servil, submissa e escravizada, subtrai o corpo colonial de subjetividade e sufoca qualquer construção de si.

O corpo da mulher negra escravizada ocupa um lugar diverso do corpo branco, o que permanece mesmo após a abolição da escravatura. O que poderia ser considerado passado, histórias ou lembranças do período colonial permanecem vivas no imaginário social e adquirem novas roupagens em uma ordem social que mantém intactas as relações de gênero, segundo a cor e a raça instituídas no período escravocrata (CARNEIRO, 2005). O lugar ocupado pelo corpo negro feminino é submetido a exclusão e exploração, demarcado

O lugar natural do grupo branco dominante são moradias saudáveis, situadas nos mais
belos recantos da cidade ou do campo e devidamente protegidas por diferentes formas
de policiamento que vão desde os feitores, capitães do mato, capangas, etc., até a
polícia formalmente constituída. Desde a casa grande e do sobrado até os belos
edifícios e residências atuais, o critério tem sido o mesmo. Já o lugar natural no negro
é o oposto, evidentemente: da senzala às favelas, cortiços, invasões, alagados e
conjuntos "habitacionais" (...) dos dias de hoje, o critério tem sito simetricamente o
mesmo: a divisão racial do espaço (GONZALES, 1982, p. 15)

Desse modo, uma cruel forma de atravessar a existência da mulher negra foi o controle do seu corpo, o que possui imbricada relação com o território do embranquecimento, em que a violência sexual cometida contra mulheres escravizadas deu origem a um processo de "mestiçagem"1 brasileira. É nesse contexto que surge o mito da democracia racial brasileira², uma vez que se acreditava em uma relação natural entre mulheres negras e homens brancos, quando em verdade essas relações eram frutos de um processo contínuo de violência sexual. O imaginário da suposta harmonia racial camufla uma sociedade racialmente estratificada, e

\footnotetext{
${ }^{1}$ Neste trabalho, o termo "mestiçagem" é utilizado para designar a miscigenação entre pessoas de raças diferentes.

${ }^{2} \mathrm{O}$ mito da democracia racial no Brasil mascara a realidade por meio de uma ideia que preconiza a igualdade de direitos e oportunidades entre brancos e negros, de modo que seria então uma ferramenta que impede a problematização dos fatores de exclusão e de repressão presentes nas relações raciais brasileiras.
} 
escamoteia as relações violência contra mulheres negras e seus corpos, historicamente marcados por uma contraposição de imagens: a "mulata", a "mãe preta"4 e o trabalho braçal.

Uma vez que a racialização constrói a ideia de raça, que classifica e hierarquiza os povos em raças superiores e inferiores, ela também hierarquiza e classifica a distribuição de lugares e papeis sociais de cada sujeito ou grupo social (QUIJANO, 2005), de modo que às mulheres negras foi relegado o espaço social de subalternização, não produtoras de suas experiências históricas e políticas.

Assim, o corpo colonial da mulher negra e sua classificação como objeto a ser explorado, inclusive sexualmente, configurou mais um elemento nas relações de poder sobre brancos e negras, sustentando "uma relação que mata em vida, transformando o corpo dos sujeitos colonizados em corpos enrijecidos como os de um cadáver" (STREVA, 2016). Esse raciocínio permite a conclusão de que, se um corpo é considerado inferior, consagra-se então a ideia de superioridade de outro. No caso, o corpo superior era o corpo branco, o que estabelecia profundas diferenças de tratamento entre colonizador e colonizado. É o que LUGONES (2010) apresenta como "dicotomia hierárquica" entre o humano e o não humano, que opera por meio do binarismo: negro-branco, mulher-homem, emoção-razão, por exemplo.

\section{Mulher negra e reprodução da vida}

As relações de poder no período colonial produziram efeitos na produção dos corpos colonizados, que foram coisificados "ao ter suas culturas espezinhadas, instituições minadas, terras confiscadas, religiões assassinadas e magnificências artísticas aniquiladas" (CÉSAIRE, 2000, p. 42). Não se tratou, portanto, de mera evangelização, empreendimento filantrópico ou um projeto divino maior. A colonização dos corpos negros foi responsável por arrancá-los de seus deuses, de sua cultura, de seus hábitos e de seus saberes, ocorrendo tão somente relações de dominação, em que o colonizado era um mero instrumento de produção.

O corpo negro, introduzido em uma espiral mercantil, tinha seu destino determinado pelas transações comerciais e vivia sob constante violência simbólica, física, sexual e psíquica.

\footnotetext{
${ }^{3}$ O termo "mulata" é usado para se referir a pessoas negras de pele clara. A palavra faz referência a "mula", filhote do cruzamento de égua com jumento, de modo que compara uma pessoa negra a um animal. Existe também a expressão "mulata tipo exportação", que reforça a visão do corpo da mulher negra como mercadoria. Ambas as expressões são pejorativas e preconceituosas, e não devem ser usadas. Estão presentes neste capítulo para exemplificar a representação sexual dada ao corpo da mulher negra.

${ }^{4}$ A "mãe preta" é a mulher escravizada obrigada a amamentar e cuidar dos filhos dos senhores brancos.
} 
Mas as mulheres escravizadas sofriam de forma diferente da dos homens escravizados, de modo que:

\begin{abstract}
A postura dos senhores em relação às mulheres escravizadas era regida pela conveniência: quando era lucrativo explorá-las como se fossem homens, eram vistas como desprovidas de gênero; mas, quando podiam ser exploradas, punidas e reprimidas de modos cabíveis apenas às mulheres, elas eram reduzidas exclusivamente à sua condição de fêmea (DAVIS, 2016, p. 25).
\end{abstract}

Durante todo o período escravocrata, a utilização de mulheres escravizadas no âmbito do trabalho doméstico foi prática muito disseminada. As criadas domésticas realizavam serviços que iam desde a manutenção da limpeza da casa à amamentação e criação dos filhos dos senhores brancos. Cuidavam das crianças brancas, as alimentavam, davam-lhes vida. Eram a "mãe preta". Por outro lado, as relações de dominação extirpavam da mulher negra escravizada os cuidados com seus próprios filhos. Era comum que essas crianças fossem "vendidas e enviadas para longe, como bezerros separados das vacas" (DAVIS, 2016, p. 26).

Além do trabalho doméstico realizado na casa-grande, as mulheres escravizadas também tinham sua capacidade reprodutiva como objeto de exploração. Seriam melhor avaliadas ou não conforme sua fertilidade, pois através da reprodução garantiriam a ampliação da força de trabalho escrava. Nesse contexto, a experiência do cativeiro associava-se não só ao trabalho braçal, mas também à função reprodutiva. $\mathrm{O}$ atributo de poder aumentar o número de escravos de um senhor era levado em conta na precificação da mulher negra, já que isso aumentaria o patrimônio de seu dono.

Nos anúncios de vendas de mulheres escravizadas, eram descritas por sua capacidade de procriação. Elas foram classificadas como "escrava reprodutora", "parturiente", dentro do "período de reprodução" ou "velha demais para procriar" (HOOKS, 2020). Como eram "reprodutoras", os proprietários buscavam garantir que procriassem tantas vezes quanto fosse possível. Ainda conforme HOOKS:

A reprodução era opressora para todas as mulheres negras férteis escravizadas. Subnutridas, sobrecarregadas de trabalho, as mulheres raramente tinham uma condição física que proporcionasse um parto fácil e seguro. Gestações repetidas e sem cuidados apropriados resultavam em vários abortos espontâneos e morte (2020, p. 77).

Mulheres escravizadas grávidas ou que tinham parido recentemente eram muito valorizadas no mercado de escravos, o que fazia com que a reprodução fosse estimulada por ser rentável para o tráfico. Mas ser "escrava reprodutora" não significava que essas mulheres eram mães. 
O direito à maternidade para mulheres escravizadas era algo negado, seus filhos eram também propriedade do colonizador branco e por ele determinado seus destinos. Tornar-se mãe para escravas negras era quase impossível, pois a dominação hierarquizava tanto a reprodução quanto a maternidade, que lhe era transferida na posição de amas de leite e cuidadora das crianças brancas. Ademais, após a abolição do comércio internacional de escravizados, houve um investimento maior na reprodução natural, como alternativa para repor e ampliar o número de cativos. "Aquela com potencial para ter dez, doze, catorze ou mais filhos era cobiçada como um verdadeiro tesouro" (DAVIS, 2016, p. 25).

Vale ressaltar que, durante a gestação, as mulheres escravizadas não dispunham de tratamento diferenciado ou de um acompanhamento adequado. O que interessava aos senhores era a continuação do trabalho produtivo, sem que houvesse diferenciação entre homens e mulheres. Por essa razão:

\begin{abstract}
Não seria descabido identificar na prática do aborto e do infanticídio uma forma de resistência da escrava seja às péssimas condições oferecidas á procriação, seja ainda à inevitável condição escrava que legaria em herança aos filhos. Os infanticídios, vistos sob esse prisma, seriam, sobretudo, a única e trágica forma visualizada pela mãe escrava para livrar seus filhos da escravidão (GIACOMINI, 1988, p. 26).
\end{abstract}

Sem dúvida, a centralidade do ventre e a possibilidade da exploração sexual do corpo feminino negro influenciaram a trajetória das mulheres escravizadas e, "em certa medida, também impactaram na manutenção da liberdade de mulheres já alforriadas e das que se encontravam em vias de libertação" (MAIA; PINHEIRO, 2017). Isso porque, em alguns casos, uma gestação poderia levar as libertas e coartadas ${ }^{5}$ à perda ou usufruto da liberdade, em razão do interesse do senhor em se apossar da criança como seu novo escravo, o que mais uma vez deixa evidente a vulnerabilidade da mulher negra.

Nesse contexto de valorização da reprodução, mulheres escravizadas estéreis sofriam mais: eram vítimas de mais abusos físicos e psicológicos, uma vez que a fecundidade era considerada uma virtude. Se não podiam procriar, isso afetava diretamente o patrimônio dos senhores.

\footnotetext{
${ }^{5}$ Coartada é a escrava que parcelava o preço da sua liberdade por um período determinado de tempo e negociava as condições para sua quitação. Ela, portanto, vivia a expectativa de se tornar forra após a satisfação do acordo firmado com seu senhor. A coartação era, frequentemente, registrada pelo senhor em carta particular - o papel de corte - que ficava sob a guarda da própria escrava coartada ou de seu fiador. Em seu verso eram inseridos os recibos das parcelas oferecidas e após completar o pagamento do valor total, o papel de corte poderia ser usado como título de liberdade e registrado em cartório com o mesmo intuito ou substituído pela alforria. É importante lembrar que a escrava coartada poderia já desfrutar de autonomia "como se forra fosse", dependendo da negociação firmada com o senhor.
} 
Na lógica do sistema escravocrata, a apropriação do labor reprodutivo da mulher negra foi responsável pela manutenção material e simbólica do núcleo familiar da casa-grande. Para além de nutrir e prover a casa branca, o corpo feminino negro também foi usado para amamentar os filhos dos senhores. Assim, enquanto racismo foi o decreto para justificar que pessoas negras seriam escravizadas, sexismo foi o que designou que o destino da mulher negra seria mais árduo do que o do homem negro. Seu ventre também era cativo, tornando seu corpo objeto de múltiplas opressões e violência.

\section{Racialização do controle reprodutivo}

Na persistência de uma lógica colonial contemporânea, o corpo da mulher negra ainda é construído sobre a noção de hiperssexualização, trabalho braçal e subalternidade, revelando uma dinâmica forjada pela intersecção entre racismo e sexismo. Nessa perspectiva, o corpo feminino negro se submete a um controle social contínuo que determina as condições de vida e de saúde das mulheres negras, limitando sua autodeterminação e seus direitos.

O que poderia ser considerado como história ou reminiscências do período colonial permanece, entretanto, vivo no imaginário social e adquire novas roupagens e funções em uma ordem social supostamente democrática que mantém intactas as relações de gênero, segundo a cor e a raça instituídas no período escravista (CARNEIRO, 2005, p. 23)

O corpo, a reprodução e a sexualidade feminina são historicamente centro de disputas de poder, e a história das mulheres negras escravizadas já revelou que elas eram vistas também a partir do seu potencial reprodutivo. Mesmo passados mais de cem anos do fim da escravidão, as mulheres negras vivenciam um conjunto complexo de violações e hierarquias reprodutivas que são memórias coloniais ainda presentes. E repensar o significado de direitos reprodutivos ${ }^{6}$ para uma ação política antirracista constitui um ponto central para que essas mulheres superem injustiças sociais históricas.

\footnotetext{
${ }^{6}$ A Conferência Internacional da ONU sobre População e Desenvolvimento (CIPD), realizada no Cairo, em 1994, conferiu papel primordial à saúde e aos direitos sexuais e reprodutivos. No capítulo VII, da Plataforma de Ação do Cairo, os direitos reprodutivos "abrangem certos direitos humanos já reconhecidos em leis nacionais, em documentos internacionais sobre direitos humanos, em outros documentos consensuais. Esses direitos se ancoram no reconhecimento do direito básico de todo casal e de todo indivíduo de decidir livre e responsavelmente sobre o número, o espaçamento e a oportunidade de ter filhos e de ter a informação e os meios de assim o fazer, e o direito de gozar do mais elevado padrão de saúde sexual e reprodutiva. Inclui também seu direito de tomar decisões sobre a reprodução, livre de discriminação, coerção ou violência". Disponível em: http://bvsms.saude.gov.br/bvs/publicacoes/cartilha_direitos_sexuais_reprodutivos.pdf.
} 
Ocupando a base da pirâmide social brasileira, segundo dossiê elaborado pelo Instituto de Pesquisa Econômica Aplicada (Ipea) 7 , a mulher negra acumula os piores indicadores sociais no Brasil. Em comparação às mulheres brancas, mulheres pretas ou pardas são mais pobres, têm menos oportunidade e estão sem perspectiva de mobilidade social. Essa assimetria é resultado do racismo estrutural, que aparece na sociedade brasileira "fazendo com que mulheres negras, apesar de todo o seu potencial de luta e emancipação, continuem ocupando os piores lugares quando se trata da violação de direitos" (SILVA, 2019, p. 46).

No Dossiê Mulheres Negras: retrato das condições de vida das mulheres negras do Brasil, publicado em 2013, houve o apontamento de conquistas alcançadas no campo da igualdade de gênero e de raça, mas também a comprovação de que mulheres negras ainda são as que mais sofrem violência doméstica. O Anuário Brasileiro de Segurança Pública de $2020^{8}$ lançou dados atualizados sobre violência doméstica e feminicídio no Brasil, mostrando que a maioria das vítimas são mulheres negras e que os números aumentaram durante a pandemia do novo coronavírus.

Todo esse contexto de opressão atinge também a realidade da saúde reprodutiva ${ }^{9}$ de mulheres negras, que sofrem tanto com a invisibilidade como com o não-reconhecimento, de tal forma a existir uma hierarquia reprodutiva, que indica qual maternidade e qual corpo é mais ou menos legítimo. Na perspectiva da invisibilidade, é possível vinculá-la à "racialização dos regimes de olhar", em que a branquitude constitui um lugar de vantagem estrutural e um "ponto de vista" (LÓPEZ, 2015, p. 312), que deixa os sujeitos negros invisíveis ao olhar da sociedade e do Estado. FANON (2008, p. 105) destaca o eu criado pelo olhar racializador, em que "o esquema corporal, atacado em vários pontos, desmoronou, cedendo lugar a um esquema epidérmico racial".

\footnotetext{
${ }^{7}$ O "Dossiê Mulheres Negras: retrato das condições de vida das mulheres negras no Brasil" foi elaborado pelo Ipea em 2013 e está disponível para acesso e download gratuitos no site do instituto, no link: http://bit.ly/1gIDrKj.

${ }^{8} \mathrm{O}$ Anuário Brasileiro de Segurança Pública se baseia em informações fornecidas pelas secretarias de segurança pública estaduais, pelo Tesouro Nacional, pelas polícias civis, militares e federal, entre outras fontes oficiais da Segurança Pública. A publicação é uma ferramenta importante para a promoção da transparência e da prestação de contas na área, contribuindo para a melhoria da qualidade dos dados. Ver mais em:

https://forumseguranca.org.br/anuario-brasileiro-seguranca-publica/.

${ }^{9}$ Ainda de acordo com a Plataforma de Ação do Cairo, "a saúde reprodutiva é um estado de completo bem-estar físico, mental e social e não simples a ausência de doença ou enfermidade, em todas as matérias concernentes ao sistema reprodutivo e a suas funções e processos. A saúde reprodutiva implica, por conseguinte, que a pessoa possa ter uma vida sexual segura e satisfatória, tenha a capacidade de reproduzir e a liberdade de decidir sobre quando, e quantas vezes o deve fazer. Implícito nesta última condição está o direito de homens e mulheres de serem informados e de ter acesso a métodos eficientes, seguros, permissíveis e aceitáveis de planejamento familiar de sua escolha, assim como outros métodos, de sua escolha, de controle da fecundidade que não sejam contrários à lei, e o direito de acesso a serviços apropriados de saúde que deem à mulher condições de passar, com segurança, pela gestação e pelo parto e proporcionem aos casais a melhor chance de ter um filho sadio".
} 
Esse regime de olhar relaciona-se também com a saúde reprodutiva das mulheres negras, em que questões relacionadas ao corpo e à raça ganham dimensão de luta política e mobilizam o movimento negro no intuito de visibilizar os direitos reprodutivos como resistência na esfera pública. A saúde reprodutiva relaciona-se ao usufruto da liberdade intrínseca aos direitos sexuais e reprodutivos. No contexto das mulheres negras, essa liberdade (ou a falta dela) se articula a uma análise interseccionada entre racismo e sexismo, que conferem experiências sociais diferentes para mulheres brancas e negras.

O corpo enquanto território político supõe, na visão do feminismo negro, a concepção de que as mulheres negras compartilham um ponto de vista singular, perspectiva ancorada nas diferenças reunidas em seus próprios corpos, que conjugam as dores e os paradoxos que marcaram, historicamente, as vidas dessas mulheres na diáspora (LÓPEZ, 2015).

As mobilizações negras contemporâneas questionam as condições nas quais as escolhas reprodutivas das mulheres negras se dão e reafirmam a recusa em colocar a mulher negra no lugar de "não sujeito". Pensar a liberdade para reprodução, nesse sentido, é avaliar os processos de decisão e escolhas reprodutivas e o entrelaçamento com o período colonial, que fez do corpo negro um corpo a serviço e portal de sujeição, e não de possibilidade de vivência democrática dos direitos reprodutivos (SOUZAS; ALVARENGA, 2007).

Acerca da hierarquia reprodutiva, em especial relacionada à especificidade das trajetórias de mulheres negras, o racismo tem sido elemento fundamental nos processos de exclusão dessas mulheres em acessar direitos reprodutivos. O movimento feminista negro traz para análise o debate sobre essa parcela da população feminina que já foi alvo preferencial da política de esterilização forçada, detém os maiores índices de mortalidade materna e maiores dificuldades no acesso à saúde. Ademais, conferiu visibilidade a temas como a qualidade da assistência ao ciclo gravídico-puerperal e a violência obstétrica.

A reivindicação por direitos reprodutivos passou a configurar estratégia política, ressaltando que direitos reprodutivos e direitos sexuais não se confundem, uma vez que aqueles dizem respeito à igualdade e à liberdade na esfera da vida reprodutiva, e estes referem-se à igualdade e à liberdade no exercício da sexualidade (ÁVILA, 2003). No que tange a esterilização compulsória, que ocorreu no Brasil nas décadas de 80/90, ela representou uma técnica utilizada pelo governo brasileiro para controlar a natalidade, utilizando sobretudo mulheres negras, conforme estudos de importantes ativistas negras ${ }^{10}$.

\footnotetext{
${ }^{10}$ Estudos apresentados por Edna Roland, intitulado "Direitos reprodutivos e racismo no Brasil".
} 
A pesquisa "Nascer no Brasil: Inquérito Nacional sobre o Parto e o Nascimento"11 evidencia que a mortalidade materna também tem maior incidência entre as mulheres negras, além de sofrerem mais com o pré-natal inadequado, menos informação sobre o trabalho de parto e sobre as complicações na gravidez. A população negra feminina tem duas vezes mais chance de morrer por causas relacionadas à gravidez, ao parto e ao pós-parto do que mulheres brancas (BRITO, 2018), muitas vezes por problemas que poderiam ter sido identificados no pré-natal. Segundo a OMS (Organização Mundial da Saúde), 92\% dos óbitos maternos são evitáveis (OPAS, 2018).

E apesar de o Brasil ter reduzido os números de mortalidade materna nos últimos anos, ainda não conseguiu atingir a meta estabelecida pela ONU (Organização das Nações Unidas). Hoje, no país, o índice de mortalidade está em 64,5 óbitos para cada 100 mil nascidos vivos número bem acima da meta firmada pela Organização, que é de 30 óbitos para cada 100 mil nascido vivos até 2030, conforme os Objetivos do Desenvolvimento Sustentável (OPAS, 2018).

Como parte de mais um exemplo das opressões que promovem a injustiça reprodutiva no Brasil está a pandemia causada pelo novo coronavírus. O $11^{\circ}$ encontro do Comitê de Acompanhamento da Covid- $19^{12}$ revelou que a mortalidade materna de mulheres negras por Covid-19 é duas vezes maior que a de mulheres brancas. Entre as gestantes negras hospitalizadas, 14,2\% foram a óbito. Entre as brancas, o desfecho morte foi observado para 7\%, ou seja, metade dos casos (CONSELHO NACIONAL DE SAÚDE, 2020).

Os dados acima são alguns exemplos de como o Estado controla os corpos femininos, em especial das mulheres negras. Esse controle aparece igualmente na trajetória reprodutiva dessas mulheres, que muitas vezes se veem impedidas de exercer seus direitos reprodutivos de forma plena e autônoma. E a avaliação dos processos de decisão e escolha reprodutivas da

\footnotetext{
${ }^{11}$ A pesquisa "Nascer no Brasil: Inquérito Nacional sobre o Parto e o Nascimento" foi coordenada pela Fundação Oswaldo Cruz e realizada com a participação de renomados pesquisadores de um grande número de instituições cientificas do país. Teve como objetivo conhecer os determinantes, a magnitude e os efeitos das intervenções obstétricas no parto, incluindo as cesarianas desnecessárias; descrever a motivação das mulheres para opção pelo tipo de parto; as complicações médicas durante o puerpério e período neonatal; bem como descrever a estrutura das instituições hospitalares quanto à qualificação dos recursos humanos, disponibilidade de insumos, equipamentos, medicamentos e unidade de terapia intensiva (UTI) para adultos e neonatos. Foi a primeira pesquisa a oferecer um panorama nacional sobre a situação da atenção ao parto e nascimento no Brasil. A coleta de dados se iniciou em fevereiro de 2011 e terminou em outubro de 2012 . Ver mais em http://www.ensp.fiocruz.br/portal-ensp/informe/site/arquivos/anexos/nascerweb.pdf, e também em http://www5.ensp.fiocruz.br/biblioteca/dados/txt_943835885.pdf.

12 O Comitê de Acompanhamento da Covid-19 foi instituído com o objetivo de concentrar informações e orientar o corpo funcional acerca das medidas tomadas para prevenir o contágio pelo Coronavírus. Ver mais em: https://conselho.saude.gov.br/ultimas-noticias-cns/1317-mortalidade-materna-por-covid-entre-negras-e-duasvezes-maior-que-entre-brancas-diz-doutora-em-saude-durante-live-do-cns.
} 
mulher negra deve ser vinculada a um campo em que se refletem a dominação e sujeição de corpos negros femininos.

Consoante Souzas e Alvarenga (2007), é possível considerar que "mulheres negras têm uma história de vida pública, inscrita em trabalhos forçados e desqualificados" e que "elas partem para organizar sua vida privada como tarefa histórica", tendo em vista que decisões acerca de seu destino e de seu corpo foram historicamente tomadas por terceiros, subtraindo sua capacidade de operar escolhas.

Um Estado que tem o poder de evitar mortes maternas, mas escolhe o exercício contínuo de mortalidade, sabendo quem são as vítimas, demonstra que seu projeto central não é a luta pela equidade, mas a instrumentalização generalizada da existência humana e a distribuição seletiva da morte (MBEMBE, 2018). Mulheres negras historicamente são consideradas menos legítimas de humanidade e, por consequência, o contexto que envolve gravidez, parto e puerpério tende a ser marcado por opressão e negligência, ainda em funcionamento pela atualização das estruturas de dominação impostas desde o colonialismo.

Nessa perspectiva, a luta das mulheres negras contra a opressão interseccionada entre gênero e raça almeja, dentre outras, a defesa do pleno gozo e exercício dos direitos reprodutivos, desconstruindo as visões estereotipadas dessas mulheres e condenando a instrumentalização generalizada dos corpos femininos negros, pois o racismo também hierarquiza a reprodução.

O direito à saúde é debate intrínseco à mulher negra, "a partir do que impulsiona discussões sobre o direito à vida, os direitos sexuais e reprodutivos, considerando que o racismo e o sexismo imprimem marcas diferenciadas no exercício desses direitos" (WERNECK, 2010). E para garantir o acesso de mulheres negras ao direito constitucional à saúde, deve haver participação efetiva não só do Estado, mas também da sociedade civil.

O setor público tem por dever assumir compromissos mais eficazes e palpáveis de combate ao racismo e às desigualdades dele decorrentes, o que poderia ser possível através da capacitação de profissionais de saúde, produção de conhecimento científico, informação à população e atenção à saúde. Para além do investimento financeiro, o investimento humano é fundamental para fortalecer a abordagem acerca do racismo e do sexismo, em clara e potente atitude para proteção do corpo feminino negro.

\section{Conclusão}

A experiência vivida pela mulher negra durante o período escravocrata brasileiro revelou como seu corpo era controlado e explorado pelo colonizador branco por diversas 
formas, seja através do trabalho braçal, seja através da exploração sexual. A objetificação do corpo feminino negro o colocou enquanto território a ser colonizado, demonstrando o quão central ele era em uma lógica de poder desde o período colonial.

Nota-se, portanto, que o processo escravagista desumanizou as pessoas negras, em especial as mulheres. Coisificado, hipersexualizado, dominado e torturado, o corpo negro feminino foi historicamente construído e talhado para o labor extenuante ou para o prazer, em uma dinâmica que também enxergou o seu sistema reprodutivo como possibilidade de exploração. Ocupando um lugar de inferioridade e desvalorização, ao corpo de mulheres negras não era admitido qualquer lugar no sistema social.

Gestar e parir mão-de-obra escrava, assim como cuidar e amamentar os filhos dos senhores brancos, também representou lucro e mais um mecanismo de manutenção das relações de poder sobre o corpo da mulher negra, que não tinha qualquer autonomia sobre sua reprodução e sobre seus filhos. Mesmo após a abolição da escravatura, as mulheres negras não se viram livres do racismo, do sexismo e dos estereótipos herdados da escravidão. Foram elas as maiores vítimas da esterilização em massa ocorrida no Brasil e que acumulam as maiores taxas de mortalidade materna, inclusive durante a pandemia do novo coronavírus. O controle sobre seus corpos é permanente e atual.

Assim, a experiência corporificada da mulher negra constitui ponto crucial para uma reflexão acerca do corpo feminino negro como uma dimensão central das disputas políticas, no sentido de desracializar o controle reprodutivo e pluralizar nossas sociedades conferindo medidas concretas de proteção aos direitos reprodutivos da mulher negra, orientando a formulação de políticas públicas mais sensíveis às suas particularidades, principalmente no que tange à complexidade de vínculos, pertencimentos e histórias das mulheres negras.

A emancipação da mulher negra e o pleno exercício de seus direitos reprodutivos incluem a emancipação feminina em busca do direito à escolha, que historicamente lhes foi negado e tem o racismo como eixo estruturante. Para que mulheres negras efetivem o livre exercício dos direitos reprodutivos é necessário que outros direitos também lhes sejam garantidos, como a igualdade de raça e de gênero, reafirmando sua capacidade reprodutiva e seu direito de escolha.

Para isso, é necessária uma reformulação da abordagem acerca do racismo junto à sociedade, a começar pelas escolas, ofertando atualização e aprendizagem participativa para a identificação de lacunas de conhecimento e posterior desenvolvimento de debates acerca do tema. E, principalmente, o estabelecimento de ferramentas capazes de estimular uma nova cultura social não discriminatória e efetivamente democrática. Grandes e profundas 
transformações sociais exigem reformulação do modo como uma população vê sua história, e o corpo da mulher negra não alcançará plena liberdade e autonomia se sua humanidade não for conhecida e reconhecida.

\section{Referências}

ÁVILA, Maria Betânia. Direitos sexuais e reprodutivos: desafios para as políticas de saúde. Cad. Saúde Pública, Rio de Janeiro, v. 19, supl. 2, S465-9, 2003. Disponível em: https://www.scielo.br/pdf/csp/v19s2/a27v19s2.pdf. Acesso em: 10 nov. 2020.

BRITO, Débora. Maioria de mortes maternas no país ocorre entre mulheres negras jovens: mulheres negras têm duas vezes mais chances de morrer por gravidez. Disponível em: https://agenciabrasil.ebc.com.br/saude/noticia/2018-05/maioria-de-mortes-maternas-no-paisocorre-entre-mulhere-negras-jovens. Acesso em: 12 nov. 2020.

CARNEIRO, Sueli. Enegrecer o feminismo: a situação da mulher negra na américa latina a partir de uma perspectiva de gênero. In: Ashoka Empreendimentos Sociais; Takano Cidadania (Orgs.). Racismos Contemporâneos. Rio de Janeiro: Takano Editora, 2003.

CÉSAIRE, Aimé. Discourse on Colonialism [1950]. Traduzido por Joan Pinkham. Nova Iorque: Monthly Review Press, 2000.

CNS - Conselho Nacional de Saúde. "Mortalidade materna por Covid entre negras é duas vezes maior que entre brancas", diz doutora em Saúde durante live do CNS. Disponível em: https://conselho.saude.gov.br/ultimas-noticias-cns/1317-mortalidade-materna-porcovid-entre-negras-e-duas-vezes-maior-que-entre-brancas-diz-doutora-em-saudedurante-live-do-cns. Acesso em: 12 nov. 2020.

DAVIS, Angela. Mulheres, raça e classe. Trad. Heci Regina Candiani. 1 ed. São Paulo: Boitempo, 2016.

FANON, Frantz. Pele negra, máscaras brancas. Salvador: EDUFBA, 2008.

FANON, Frantz. The Wretched of the Earth. Tradução por Richard Philcox, com comentário de Jean-Paul Sartre e Homi K. Bhabha. Título original: "Les Damnés de la terre". New York: Grove Press, 2004.

GIACOMINI, Sonia Maria. Mulher e escrava: Uma Introdução ao Estudo da Mulher Negra no Brasil. Rio de Janeiro: Vozes. 1988.

GONZALEZ, Lélia. A mulher negra na sociedade brasileira. In: LUZ, Madel T. (Org). O lugar da mulher: estudos sobre a condição feminina. Rio de Janeiro: Edições Graal, 1982.

HOOKS, Bell. E eu não sou uma mulher? Mulheres negras e feminismo. Trad. Bhuvi Libanio. $5^{\text {a }}$ ed. Rio de Janeiro: Rosa dos Tempos, 2020. 
LÓPEZ, Laura Cecilia. C. O corpo colonial e as políticas e poéticas da diáspora para compreender as mobilizações afro-latino-americanas. Horizontes Antropológicos, Porto Alegre, ano 21, n. 43, p. 301-330, jan./jun. 2015.

LUGONES, Maria. Toward a decolonial feminism. Hypatia, vol. 25, n. 4, 2010.

MAIA, Ludmila de Souza; PINHEIRO, Fernanda Domingos. Cativas do corpo, libertas pelo trabalho: casos de mulheres de cor nas fronteiras entre escravidão e liberdade (Mariana, séculos XVIII e XIX). Dossiê: Conservadorismo, Direitos, Moralidades e Violência, Campinas, n. 50, 2017. Disponível em:

https://periodicos.sbu.unicamp.br/ojs/index.php/cadpagu/issue/view/1449. Acesso em: 02 nov. 2020.

MBEMBE, Achille. Necropolítica. 3. ed. São Paulo: n-1 edições, 2018.

OPAS BRASIL - Organização Pan-Americana da Saúde. Folha informativa - Mortalidade materna. Disponível em:

https://www.paho.org/bra/index.php?option=com_content\&view $=$ article\&id=5741:folhainformativa-mortalidade-

materna\&Itemid=820\#: :text=A\%20maioria $\% 20$ das $\% 20$ mortes $\% 20$ maternas,nas $\% 20$ semana s\%20ap\%C3\%B3s\%20o\%20parto.. Acesso em: 12 nov. 2020.

QUIJANO, Aníbal. Colonialidade do poder, eurocentrismo e América Latina. En: Lander, Edgar (Org). A colonialidade do saber: eurocentrismo e ciências sociais. Perspectivas latinoamericanas. Colección Sur Sur, CLACSO, Ciudad Artónoma de Buenos Aires, Argentina. Setembro, 2005.

ROLAND, Edna. Direitos reprodutivos e racismo no Brasil. Revista Estudos Feministas, vol. 3, n. 2, Rio de Janeiro, 1995.

SILVA, Aparecida da. O protagonismo das mulheres quilombolas na luta por direitos em comunidades do Estado de São Paulo (1988-2018). 2019. 151 f. Tese (Doutorado em História Social) - Pontifícia Universidade Católica de São Paulo, São Paulo, 2019.

SOUZAS, Raquel; ALVARENGA, Augusta Thereza de. Direitos sexuais, direitos reprodutivos: concepções de mulheres negras e brancas sobre liberdade. Saúde e sociedade, São Paulo, v.16, n.2, p.125-132, 2007.

STREVA, Juliana Moreira. Colonialidade do ser e corporalidade: o racismo brasileiro por uma lente descolonial. Revista Antropolítica, n. 40, Niterói, p. 20-53, 1. sem. 2016.

WERNECK, Jurema. De Ialodés y feministas. Reflexiones sobre el acionar de las mujeres negras em América Latina y el Caribe, en: Féminismes dissidentes em Amérique Latine et la Caraibe. Nouvelles Questions Féministes, vol. 24, n. 2, Paris: 2005.

WERNECK, Jurema. Mulheres negras: um olhar sobre as lutas sociais e as políticas públicas no Brasil. Rio de Janeiro: Criola, 2010. 
Data de recebimento: 03.02.2021

Data de aprovação: 20.07.2021 